\title{
High-performance, reliable, 730-nm-emitting Al-free active region diode lasers
}

\author{
A. Al-Muhanna, ${ }^{\text {a) }}$ J. K. Wade, T. Earles, J. Lopez, and L. J. Mawst \\ Reed Center for Photonics, University of Wisconsin-Madison, Madison, Wisconsin 53706
}

(Received 1 July 1998; accepted for publication 14 September 1998)

\begin{abstract}
Compressively strained InGaAsP quantum well $(\mathrm{QW})$ active $(\lambda=732 \mathrm{~nm})$ diode lasers achieve 2.9 $\mathrm{W}$ continuous wave $(\mathrm{cw})$ power from facet-coated $(4 \% / 95 \%) 100-\mu \mathrm{m}$-wide apertures, with reliable operation demonstrated at $0.5 \mathrm{~W} \mathrm{cw}$ power. A broad waveguide structure is used to obtain a large transverse spot size $(d / \Gamma=0.433 \mu \mathrm{m})$, resulting in a low internal loss $\left(\alpha_{i} \sim 2 \mathrm{~cm}^{-1}\right)$ and narrow transverse far-field beam width $\left(\theta_{1 / 2}=38^{\circ}\right)$. Record-high characteristic temperatures for the threshold current and the differential quantum efficiency $\left(T_{0}=115 \mathrm{~K}\right.$ and $\left.T_{1}=285 \mathrm{~K}\right)$ are obtained by growing on misoriented substrates. (C) 1998 American Institute of Physics.
\end{abstract}

[S0003-6951(98)00946-2]

High power diode lasers emitting in the wavelength region $\lambda=730-760 \mathrm{~nm}$ are needed for applications ranging from high-resolution printing to photodynamic therapy (PDT). For $\lambda<780 \mathrm{~nm}$, diode lasers typically have $\mathrm{Al}_{x} \mathrm{Ga}_{1-x} \mathrm{As}$ active regions with high $\mathrm{Al}$ concentrations $(x$ $>0.15)$ necessary for shorter wavelengths. The high surface-recombination velocity for $\mathrm{AlGaAs}^{1}$ leads to low power densities at catastrophic optical mirror damage (COMD). The internal power densities at COMD, $\bar{P}_{\mathrm{COMD}}$, have been determined for both GaAs- and $\mathrm{Al}_{x} \mathrm{Ga}_{(1-x)} \mathrm{As}-$ active $(\lambda=810-780 \mathrm{~nm})$ diode lasers: $11 \mathrm{~mW} / \mathrm{cm}^{2}$ and $8-5$ $\mathrm{mW} / \mathrm{cm}^{2}(x=0.07-0.10)$, respectively, for conventionally passivated devices. $^{2,3}$ That is, even small Al concentrations lead to significant reductions in $\bar{P}_{\mathrm{COMD}}$. Shorter wavelengths, requiring greater $\mathrm{Al}$ concentrations, are expected to lead to further reductions in $\bar{P}_{\mathrm{COMD}}$ and thus, significantly lower reliable operating powers. As a result, for $700 \mathrm{~nm}$ $<\lambda \leqslant 780 \mathrm{~nm}$ there are no extensive life test data and high power devices are not commercially available.

Promising alternatives are diode lasers with AlGaInAsor InGaAsP-active regions: both are resistant to the motion of dark-line defects. Compressively strained AlGaInAsactive region $(\lambda \sim 730 \mathrm{~nm})$ diode lasers with $100-\mu \mathrm{m}$-wide stripes demonstrated $2.2 \mathrm{~W}$ continuous wave $(\mathrm{cw})$ power and preliminary constant power $(0.25 \mathrm{~W})$ life-test data indicating stable operation up to $\sim 300 \mathrm{~h} .{ }^{4}$ However, the presence of aluminum in the active region may inhibit long-life, high power operation. InGaAsP-active $(\lambda=805 \mathrm{~nm})$ diode lasers recently achieved $\mathrm{cw}$ power levels up to $8.8 \mathrm{~W}$ where COMD was reached $\left(\bar{P}_{\text {COMD }} \sim 18 \mathrm{MW} / \mathrm{cm}^{2}\right),{ }^{5}$ twice that of AlGaAs-active devices. Thus, the use of an InGaAsP quantum well $(\mathrm{QW})$ active region offers the intriguing possibility of realizing reliable high-power operation at short wavelengths $(\lambda \sim 730-780 \mathrm{~nm})$. We report here high performance $\lambda=732 \mathrm{~nm}$ lasers and demonstrate stable operation $(>700 \mathrm{~h})$ at $0.5 \mathrm{~W} \mathrm{cw}$ power.

The laser structure shown in Fig. 1 is grown by lowpressure (50 mbar) metalorganic chemical vapor deposition

a)Electronic mail: al-muhan@cae.wisc.edu
(LP-MOCVD) at a growth temperature of $700{ }^{\circ} \mathrm{C}$. The structure consists of a $150 \AA$ compressively strained $(\Delta a / a$ $\approx 1.4 \%$ ) InGaAsP QW surrounded by $200 \AA \operatorname{In}_{0.5} \mathrm{Ga}_{0.5} \mathrm{P}$ transition layers. The InGaAsP/GaAs material system has small band-gap differences resulting in severe carrier leakage which causes a high threshold current density, low internal quantum efficiency, and poor temperature behavior. Therefore, high band-gap $\operatorname{In}_{0.5}\left(\mathrm{Ga}_{0.5} \mathrm{Al}_{0.5}\right)_{0.5} \mathrm{P}(0.75 \mu \mathrm{m})$ cladding layers and an $\operatorname{In}_{0.5}\left(\mathrm{Ga}_{0.9} \mathrm{Al}_{0.1}\right)_{0.5} \mathrm{P}(0.8 \mu \mathrm{m})$ confining layer are used to suppress carrier leakage. ${ }^{5}$

Broad-stripe, 100- $\mu \mathrm{m}$-wide, devices are fabricated and tested under low duty-cycle pulsed-current conditions to determine the device characteristics as a function of cavity length: Figure 2 shows the variation of the threshold current density, $J_{\text {th }}$, and external differential quantum efficiency, $\eta_{d}$, with device length, $L$. At $20^{\circ} \mathrm{C}, J_{\text {th }}=450 \mathrm{~A} / \mathrm{cm}^{2}$ and $\eta_{d}=65 \%$ for 1 -mm-long devices. The threshold current density is higher than that of previously reported 730-nmAlGaInAs-active devices, ${ }^{4} J_{\text {th }}=281 \mathrm{~A} / \mathrm{cm}^{2}$. This is due to the fact that the device structures reported here are designed for high output power operation with a large transverse spot size $(d / \Gamma=0.43 \mu \mathrm{m}), 1.6$ times larger than previous structures. ${ }^{4}$ Using published relationships ${ }^{6}$ between $J_{\text {th }}$, the transparency current density, $J_{T}$, and gain saturation parameter, $G_{0}$ :

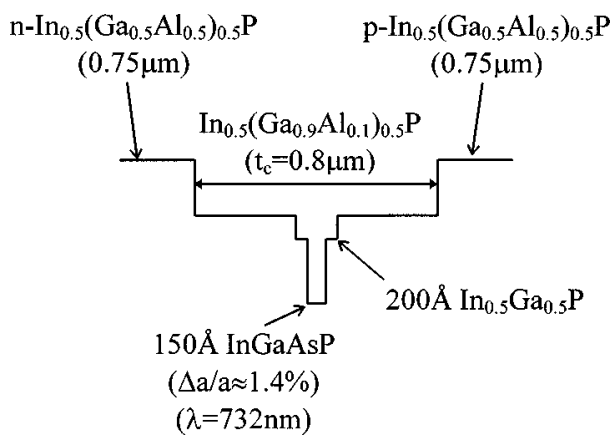

FIG. 1. Schematic diagram of Al-free active-region 730-nm-laser structure with broad-waveguide design. 


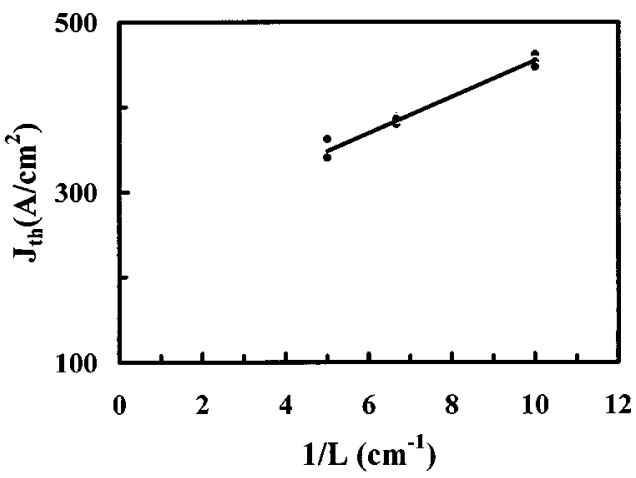

(a)

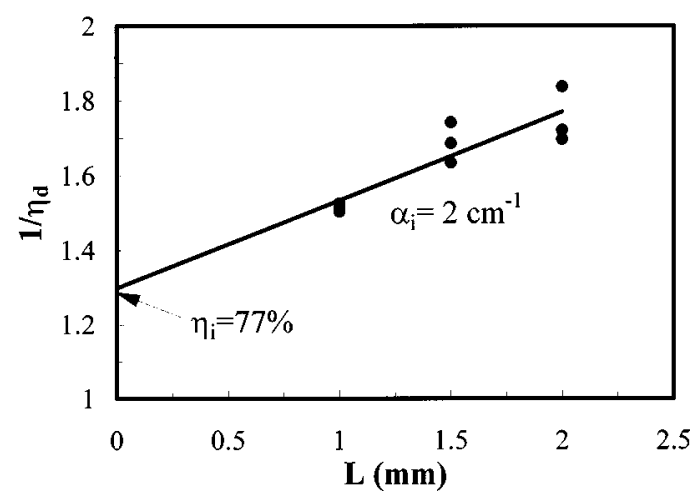

FIG. 2. Measured length dependence of threshold current density, $J_{\text {th }}$, and external differential quantum efficiency, $\eta_{d}$, as a function of device cavity length, $L$. (a) Fitted curve for threshold current density, $J_{\text {th }}$, vs $1 / L$; (b) inverse of external differential quantum efficiency, $\eta_{d}$, as function of device length, $L$.

$$
J_{\mathrm{th}}=\frac{J_{T}}{\eta_{i}} \exp \left(\frac{\alpha_{i}+\frac{1}{L} \ln \left(\frac{1}{R}\right)}{\Gamma G_{0}}\right),
$$

where $\eta_{i}, \alpha_{i}$, and $\Gamma$ are the internal efficiency, the internal loss, and optical confinement factor, respectively. A best fit to the measured data gives $J_{T}=187 \mathrm{~A} / \mathrm{cm}^{2}$ and $\Gamma G_{0}$ $=23 \mathrm{~cm}^{-1}$.

As shown in Fig. 2(b), a broad waveguide $(0.8 \mu \mathrm{m})$ design allows for low internal losses $\left(\alpha_{i}=2 \mathrm{~cm}^{-1}, \eta_{i}\right.$ $=77 \%$ ) with a large transverse spot size $(d / \Gamma=0.43 \mu \mathrm{m})$. The use of $\operatorname{In}_{0.5}\left(\mathrm{Ga}_{0.5} \mathrm{Al}_{0.5}\right)_{0.5} \mathrm{P}$ cladding layers result in high values for the characteristic temperature coefficients of the threshold current and external differential quantum efficiency $\left[T_{0}=115 \mathrm{~K}\right.$ and $T_{1}=285 \mathrm{~K}$ (Fig. 3) $]$ compared to those for $\mathrm{Al}_{0.6} \mathrm{Ga}_{0.4} \mathrm{As}$ clad devices ${ }^{4}\left(T_{0}=37 \mathrm{~K}\right.$ and $T_{1}=63$ $\mathrm{K})$. The improvement is most likely due to the superior carrier confinement provided by the $\operatorname{In}_{0.5}\left(\mathrm{Ga}_{0.5} \mathrm{Al}_{0.5}\right)_{0.5} \mathrm{P}$ cladding layers. Even though the direct gap of $\mathrm{Al}_{x} \mathrm{Ga}_{1-x} \mathrm{As}$ may be larger, the indirect $X$ valley $(x>0.45)$ is at a lower energy, thereby, increasing the carrier leakage. ${ }^{7}$ Because the $X$ valley is relatively constant with composition, there is little, if any, reduction in carrier leakage for $\mathrm{Al}$ compositions greater than $\sim 45 \%$. Thus, our $\operatorname{In}_{0.5}\left(\mathrm{Ga}_{0.5} \mathrm{Al}_{0.5}\right)_{0.5} \mathrm{P}$ cladding layers provide barrier heights $\sim 200 \mathrm{meV}$ larger than that obtainable from high Al composition AlGaAs.

The structure used here is similar to that previously reported ${ }^{8}$ except it is grown on (100) substrates misoriented Downloaded 08 Feb 2007 to 128.104.198.19. Redistribution subject

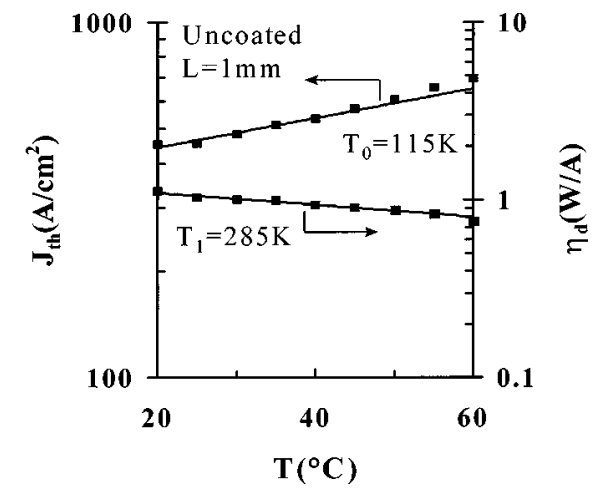

FIG. 3. Best-fit analysis for $J_{\text {th }}$ and $\eta_{d}$ vs temperature for 1-mm-long devices.

$10^{\circ}$ towards $\langle 111\rangle \mathrm{A}$. Growth on highly misoriented substrates completely disorders $\operatorname{InGa}(\mathrm{Al}) \mathrm{P}$ increasing the band gap by $\sim 70 \mathrm{meV}{ }^{9}$ The larger band gap further reduces carrier leakage from the quantum well leading to a low temperature sensitivity for this wavelength region. Comparison between this device and the same structure grown on slightly miscut substrates $\left[(100) 0.5^{\circ}\right.$ towards $\left.\langle 110\rangle\right],{ }^{8}$ Table I, shows the benefit of using highly misoriented substrates in improving device performance. The improvement in $J_{\text {th }}, T_{0}$, and $T_{1}$ reflect the strong carrier confinement, which is critical for achieving high $\mathrm{cw}$ power. In addition to the increase in confinement as a result of disordering, misorientation enhances the $p$ doping of the cladding layer, ${ }^{10}$ which also improves electron confinement. However, in this study the effect is minimized since the $p$-cladding layer of the laser structure grown on the substrate with a $\frac{1}{2}{ }^{\circ}$ miscut was already highly doped $\left(p \sim 1 \times 10^{18} \mathrm{~cm}^{-3}\right)$. Other device parameters, such as $\alpha_{i}, \eta_{i}, J_{T}$, and $\Gamma G_{0}$, are unaffected by the substrate misorientation. These results are surprising considering that previous work ${ }^{11}$ on strained-layer InGaAs QW structures indicates that substrate misorientation is detrimental to device performance. The present work though is at a much shorter wavelength $(\lambda=730$ vs $980 \mathrm{~nm})$, where carrier leakage is significantly larger. While we have not examined the interfacial roughness of the InGaAsP QW in the 730-nm-laser structure, we believe the structures grown on substrates with a $10^{\circ}$ misorientation do have increased roughness but the effect is overwhelmed by the large decrease in carrier leakage resulting from the disordered materials.

High cw output power is possible as a result of the relatively large spot size, $d / \Gamma=0.433 \mu \mathrm{m}$. A cw output power as high as $2.9 \mathrm{~W}$ (Fig. 4), is achieved from facet-coated (4\%/ $95 \%)$ broad-stripe $(100 \mu \mathrm{m}$ wide $\times 1.5 \mathrm{~mm}$ long $)$ devices

TABLE I. Characteristic data of two types of lasers, 100- $\mu \mathrm{m}$-stripe width, with different substrate misorientation.

\begin{tabular}{ccc}
\hline \hline Substrate misorientation & $10^{\circ}$ towards $\langle 111\rangle \mathrm{A}$ & $0.5^{\circ}$ towards $\langle 110\rangle^{8}$ \\
$J_{\text {th }}\left(\mathrm{A} / \mathrm{cm}^{2}\right)$ & $450(1 \mathrm{~mm}$ long $)$ & $514(1 \mathrm{~mm}$ long $)$ \\
$J_{T}\left(\mathrm{~A} / \mathrm{cm}^{2}\right)$ & 187 & 173 \\
$\Gamma G_{0}\left(\mathrm{~cm}^{-1}\right)$ & 23 & 19 \\
$\alpha_{i}\left(\mathrm{~cm}^{-1}\right)$ & 2 & 3 \\
$\eta_{i}(\%)$ & 77 & 75 \\
$T_{0}(\mathrm{~K})$ & $115(1 \mathrm{~mm}$ long $)$ & $72(1 \mathrm{~mm}$ long $)$ \\
$T_{1}(\mathrm{~K})$ & $285(1 \mathrm{~mm}$ long $)$ & $153(1 \mathrm{~mm}$ long $)$ \\
$\mathrm{cw}$ power $(\mathrm{W})$ & $2.9(1.5 \mathrm{~mm}$ long $)$ & $1.4(2 \mathrm{~mm}$ long $)$ \\
\hline \hline
\end{tabular}




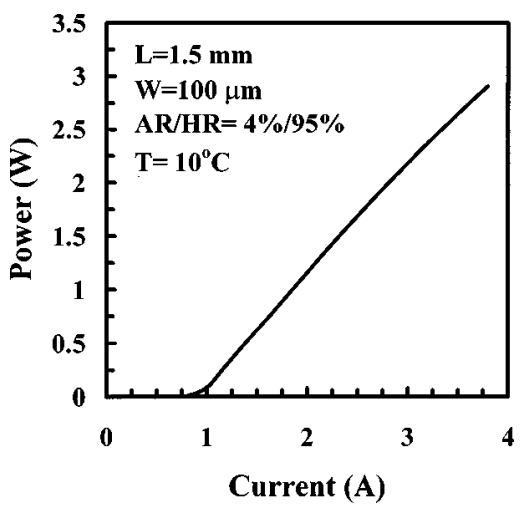

FIG. 4. cw $L-I$ characteristics for facet-coated (4\%/95\%) 730-nm-emitting quantum well $(100 \mu \mathrm{m} \times 1.5 \mathrm{~mm})$ laser.

mounted $p$-side down on diamond submounts at a heatsink temperature of $10^{\circ} \mathrm{C}$. The sudden failure observed at a power level below the $\mathrm{COMD}^{12}$ indicates the output power is limited by filamentation. The wallplug efficiency, $\eta_{p}$, reaches a maximum of $35 \%$ at an output power of $2.9 \mathrm{~W}$. The large spot size of the broad waveguide results in a relatively narrow transverse far-field pattern (Fig. 5) corresponding to a single-transverse mode with a full width at half maximum (FWHM), $\theta_{\perp}$, of $38^{\circ}$ and full width at $1 / e^{2}$ of $68^{\circ}$ over the whole range of drive current. Preliminary reliability measurements at a constant power of $0.5 \mathrm{~W}$ and held at a heatsink temperature of $25^{\circ} \mathrm{C}$ (Fig. 6) show no degradation for greater than $700 \mathrm{~h}$.

In conclusion, we have demonstrated 732-nm-emitting Al-free compressively strained active region lasers with high $\mathrm{cw}$ output power $(2.9 \mathrm{~W})$, reliable operation at a power of $0.5 \mathrm{~W}$, and record high values for the characteristic tempera-

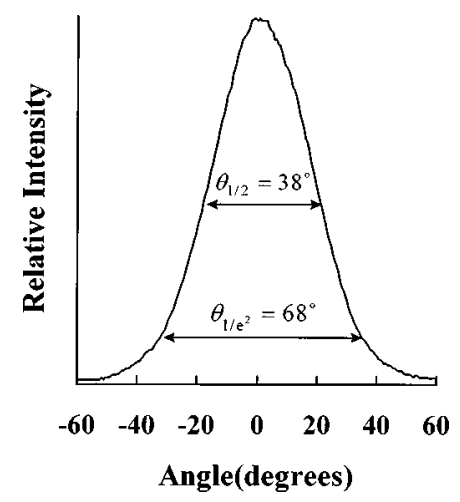

FIG. 5. Measured far-field pattern in the transverse direction. The beam is Gaussian and in good agreement with theory.

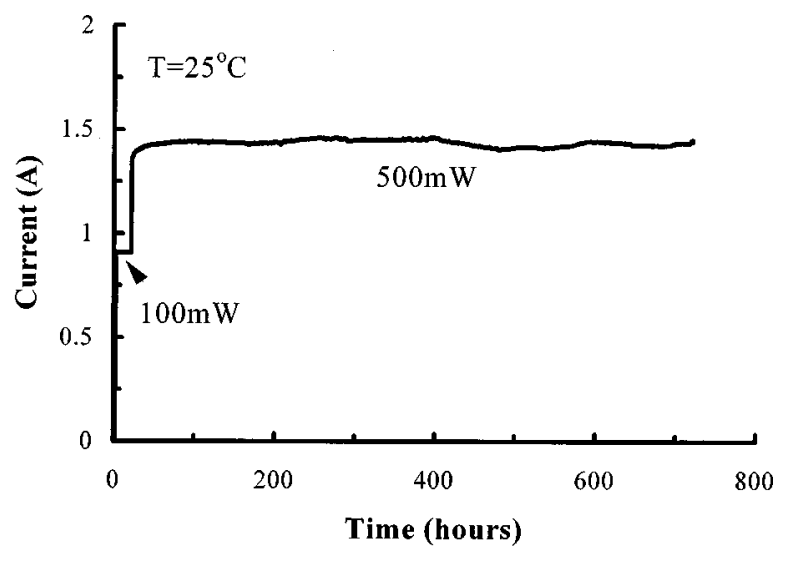

FIG. 6. Measured reliability characteristics at heatsink temperature of $25^{\circ} \mathrm{C}$ for facet-coated devices.

ture coefficients, $T_{0}(115 \mathrm{~K})$ and $T_{1}(285 \mathrm{~K})$. These results are achieved by utilizing the reliability of an Al-free active layer in conjunction with the performance enhancement of completely disordered (high band gap) confinement and cladding layers. By optimizing the strain of the QW, improving thermal management and growth uniformity to reduce filamentation, we believe it is possible to reach output powers commensurate with $\bar{P}_{\text {COMD }}$ for InGaAsP: $\sim 6 \mathrm{~W}$ for 100 $\mu \mathrm{m}$ apertures.

${ }^{1}$ R. Schatz and C. G. Bethea, J. Appl. Phys. 76, 2509 (1994).

${ }^{2}$ D. Z. Garbuzov, J. H. Abeles, N. A. Morris, P. D. Gardner, A. R. Triano, M. G. Harvey, D. B. Gilbert, and J. C. Connolly, Proc. SPIE 2682, 20 (1996).

${ }^{3}$ K. Shigihara, Y. Nagai, S. Karakida, A. Takami, Y. Kokubo, H. Matsubara, and S. Kakimoto, IEEE J. Quantum Electron. QE-27, 1537 (1991).

${ }^{4}$ M. A. Emanuel, J. A. Skidmore, M. Jansen, and R. Nabiev, IEEE Photonics Technol. Lett. 9, 1451 (1997).

${ }^{5}$ J. K. Wade, L. J. Mawst, D. Botez, and J. A. Morris, Electron. Lett. 34, 1100 (1998).

${ }^{6}$ P. W. Mcilory, A. Kurobe, and Y. Uematsu, IEEE J. Quantum Electron. QE-21, 1958 (1985).

${ }^{7}$ S. A. Wood, D. J. Someford, P. M. Smowton, C. C. Button, and P. Blood, CLEO Tech. Dig. Ser. 6, 286 (1998).

${ }^{8}$ A. Al-Muhanna, J. K. Wade, L. J. Mawst, and R. J. Fu, Appl. Phys. Lett. 72, 641 (1998).

${ }^{9}$ S. McKenan, C. B. Carter, D. P. Bour, and J. R. Shealy, J. Mater. Res. 3, 406 (1988).

${ }^{10}$ D. P. Bour, R. S. Geels, D. W. Treat, T. L. Paoli, F. Ponce, R. L. Thornton, B. S. Krusor, R. D. Bringans, and D. F. Welch, IEEE J. Quantum Electron. QE-30, 593 (1994).

${ }^{11}$ A. Bhattacharya, L. J. Mawst, S. Nayak, J. Li, and T. F. Keuch, Appl. Phys. Lett. 68, 2240 (1996).

${ }^{12}$ J. K. Wade, L. J. Mawst, D. Botez, R. F. Nabiev, M. Jansen, and J. A. Morris, Appl. Phys. Lett. 72, 4 (1998). 